\title{
Kidney failure after lung transplantation in systemic scleroderma: a case report with literature review
}

Takashi Ishide ${ }^{1}$, Hiroshi Nishi ${ }^{1 *}$, Hiroko Ambe ${ }^{1}$, Kenjiro Honda ${ }^{1}$, Motonobu Nakamura$^{1}$, Jiro Sato ${ }^{2}$, Kota Yamamoto $^{3}$, Masaaki Sato ${ }^{4}$ and Masaomi Nangaku ${ }^{1}$

\begin{abstract}
Background: Systemic scleroderma (SSc) involves multiple organs including the skin, the lung, the kidney, and the esophagus. Nowadays, patient life prognosis has substantially improved due to more appropriate management of lung complications, including lung transplantation. However, the extension of their survival may increase SSC patients with chronic kidney diseases and requiring renal replacement therapy (RRT).

Case presentation: A 51-year-old female with SSC who underwent unilateral deceased-donor lung transplantation was referred because of progressive renal dysfunction. Despite no episodes of scleroderma renal crisis, her renal function gradually deteriorated for 2 years with her serum creatinine level increasing from $0.5 \mathrm{mg} / \mathrm{dL}$ at transplantation to $4.3 \mathrm{mg} / \mathrm{dL}$. Although we reinforced antihypertensive treatment and reduced calcineurin inhibitor dose, she thereafter developed symptomatic uremia. Due to impaired manual dexterity with contracture of the interphalangeal joints, no caregivers at home, and kidney transplantation donor unavailability, maintenance hemodialysis was chosen as RRT modality. Further, due to the narrowing of superficial vessels in the sclerotic forearm skin and post-transplant immunocompromised status, the native left brachiocephalic arteriovenous fistula was created. Post-operative course was uneventful while any sign of cutaneous infection and pulmonary hypertension was closely monitored. Our literature review also indicates several difficulties with initiating and maintaining RRT in patients with SSC although case reports of kidney failure after lung transplanation in SSc were not accumulated.

Conclusions: With respect to initiating RRT for post-lung transplant patients with SSc, the clinical course of our case exemplifies recent complex trends of renal management. The optimal modality with secured initiation of RRT should be carefully determined based on the severity and risk for the cardiopulmonary, peripheral vascular, cutaneous, and systemic or local infectious complications.
\end{abstract}

Keywords: Arteriovenous fistula, Calcineurin inhibitor, Chronic kidney disease, Lung transplantation, Systemic sclerosis

\section{Introduction}

Systemic scleroderma (SSc) is known as a systemic disorder involving the kidney as a life-threatening

\footnotetext{
*Correspondence: hrnishi-tky@umin.ac.jp

'Division of Nephrology and Endocrinology, The University of Tokyo Graduate School of Medicine, 7-3-1 Hongo, Bunkyo-ku, Tokyo 113-8655, Japan

Full list of author information is available at the end of the article
}

scleroderma renal crisis that presents with the abrupt onset of severe hypertension accompanied by rapidly progressive renal failure [1]. Antihypertensive therapy with angiotensin-converting enzyme inhibitors is highly recommended to improve life and renal prognosis [2].

(c) The Author(s). 2020 Open Access This article is licensed under a Creative Commons Attribution 4.0 International License, which permits use, sharing, adaptation, distribution and reproduction in any medium or format, as long as you give appropriate credit to the original author(s) and the source, provide a link to the Creative Commons licence, and indicate if changes were made. The images or other third party material in this article are included in the article's Creative Commons licence, unless indicated otherwise in a credit line to the material. If material is not included in the article's Creative Commons licence and your intended use is not permitted by statutory regulation or exceeds the permitted use, you will need to obtain permission directly from the copyright holder. To view a copy of this licence, visit http://creativecommons.org/licenses/by/4.0/ The Creative Commons Public Domain Dedication waiver (http://creativecommons.org/publicdomain/zero/1.0/) applies to the data made available in this article, unless otherwise stated in a credit line to the data. 
Another targeted organ is the lungs, presenting as scleroderma lung disease or pulmonary hypertension. In addition to anti-fibrotic agents such as nintedanib and pirfenidone for pulmonary fibrosis, the ultimate treatment may be lung transplantation. These modalities served to extend the life span of those patients drastically. On the other hand, aging and prolonged survival of patients with SSc conferred a variety of medical needs. For example, although not sufficiently recognized, postlung transplantation patients are the population at high risk for chronic kidney disease (CKD) [3].

Here, we describe a SSc case with a post-lung transplant CKD, eventually requiring renal replacement therapy (RRT). This report demonstrates that RRT should be designed and initiated for those patients, considering various medical and social conditions surrounding the patient.

\section{Case presentation}

A 51-year-old female was referred to our outpatient office due to severe renal dysfunction. She presented with SSc, which had manifested as digital contracture at 30 years of age. She had no medical history of scleroderma renal crisis, but further imaging studies, such as computed tomography and gastroscopy, revealed interstitial pneumonitis and gastroesophageal reflux disease. Laboratory tests showed serum positivity for anti-Scl-70 antibody. Despite conventional immunosuppressant treatment, she suffered from dyspnea because of recurrent pneumothorax and initiated home oxygen therapy at 40 years of age. Five years later, she underwent leftsided unilateral deceased-donor lung transplantation with her pre-transplant serum creatinine level of approximately $0.5 \mathrm{mg} / \mathrm{dL}$. She also had no history of hematuria or proteinuria, diabetes mellitus, or hypertension.

Her post-operative course was uneventful. Her respiratory condition improved, and home oxygen therapy was successfully withdrawn. At 2 years after transplantation, her blood pressure exceeded $150 \mathrm{mmHg}$ which was thereafter stabilized at approximately 130 $\mathrm{mmHg}$ with temocapril hydrochloride treatment, and her serum creatinine level continued to increase. Meanwhile, the trough concentration of tacrolimus was well controlled. Despite no signs of scleroderma renal crisis, her renal function gradually deteriorated, and periodic ambulant follow-ups showed increasing serum creatinine levels, from $0.8 \mathrm{mg} / \mathrm{dL}$ to $1.6 \mathrm{mg} / \mathrm{dL}$ over those 2 years. Tacrolimus was replaced by sustainedrelease tacrolimus hydrate, and the target trough value was decreased from $8-10 \mathrm{ng} / \mathrm{mL}$ to $6-8 \mathrm{ng} / \mathrm{mL}$.

After her first visit to our office, despite multidisciplinary approach, including nutritional counseling, her serum creatinine level reached $7.0 \mathrm{mg} / \mathrm{dL}$, concurrently with uremic symptoms such as nausea, vomiting, and pedal edema. Kidney transplantation was impossible at that time since she had no living or deceased kidney donor. Peritoneal dialysis (PD) was also difficult as she could neither manipulate the PD catheter and bags nor give scrupulous exit-site care well enough because of digital contraction and restricted range of motion due to SSc. Unfortunately, no family member could be supportive upon her handling the PD equipment. Finally, she chose hemodialysis (HD) as her RRT modality.

For establishing vascular access, ultrasound cardiography revealed an ejection fraction of $66 \%$ and a tricuspid regurgitation peak gradient of $20 \mathrm{mmHg}$ without any sign of pulmonary hypertension, suggesting that arteriovenous fistula (AVF) formation may confer a low risk for high cardiac output heart failure or pulmonary hypertension. The artificial devices such as cuffed hemodialysis catheter or arteriovenous graft were avoided because of the risk of infection and delayed wound healing caused by immunosuppressive agents for SSc and lung transplantation care. Upon peripheral venous ultrasonography, her forearm veins were poorly developed and the peri-vascular tissue was sclerotic so that they were insufficient for puncture and suturing, except for the elbow. Since radial and ulnar veins at her right brachium were located deeper than those at the left and she was righthanded, we concluded that left brachiocephalic AVF was the most appropriate for the patient.

The perioperative course was uneventful; the vessels were smoothly sutured without excessive surgical incision or bleeding. The AVF developed well to be clearly visible and easily punctured without any sign of upper limb swelling, arrhythmia, or deterioration of Raynaud's phenomenon. Since AVF may cause pulmonary hypertension that also potentially complicates SSc, the patient was carefully followed by cardiologists with ultrasound cardiography. The estimation of a tricuspid regurgitation peak gradient remained approximately $40 \mathrm{mmHg}$, implying a presence of moderate pulmonary hypertension according to the European guideline [4], but with no sign of right ventricular, atrial, or inferior vena cava dilation. She needed no medication and had no limitation of daily physical activities.

Two months after the operation maintenance HD was initiated (Fig. 1). Even when the blood flow rate for HD was raised from 80 to $140 \mathrm{~mL} / \mathrm{min}$, the venous pressure for returning blood stabilized at less than $60 \mathrm{mmHg}$. After confirming her uremic syndrome was ameliorated, she was discharged home. At 2 months after the initiation, neither vascular access problem nor signs of blood flow excess were reported. 


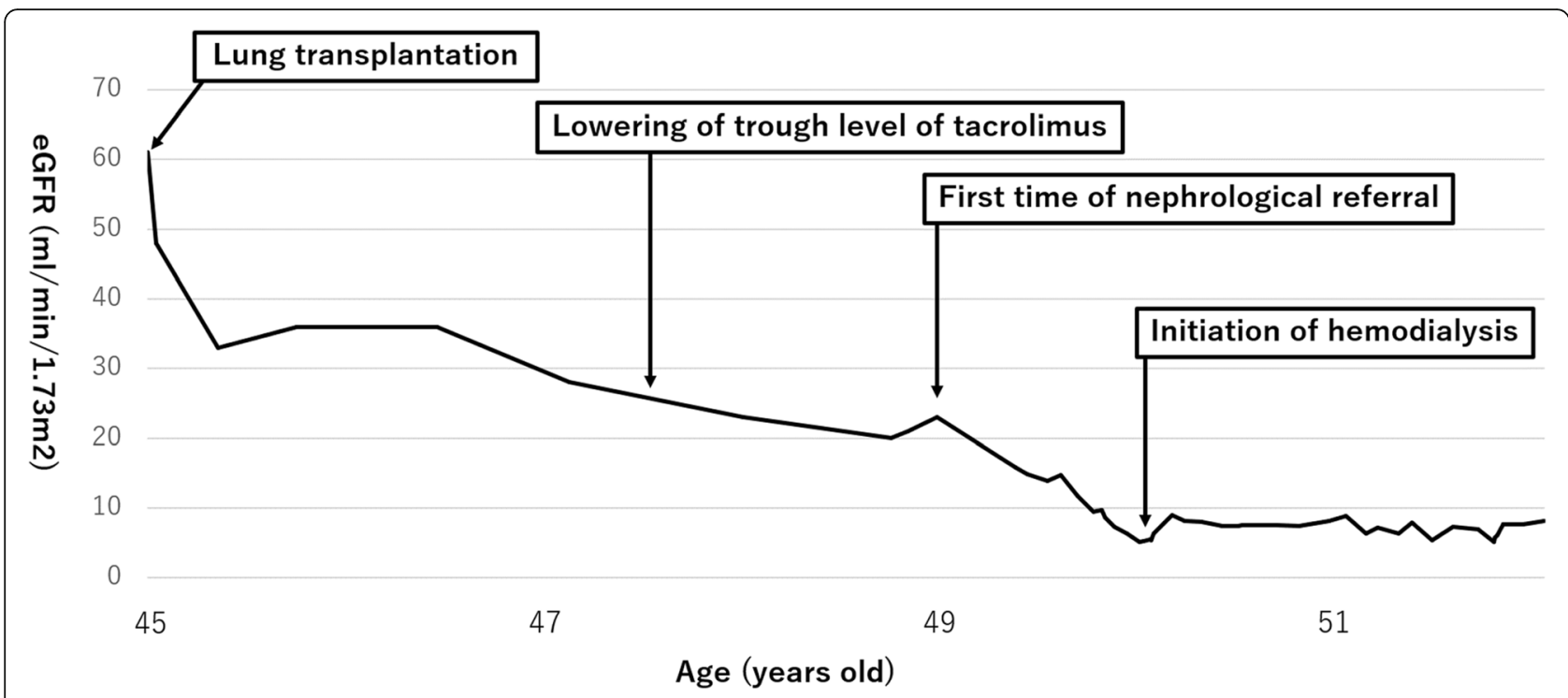

Fig. 1 The clinical course of the presented case. The serum creatinine level was $0.5 \mathrm{mg} / \mathrm{dL}$ before lung transplantation. After transplantation, it stabilized at around $0.8 \mathrm{mg} / \mathrm{dL}$. Over 2 years after transplantation, it had gradually deteriorated to $1.6 \mathrm{mg} / \mathrm{dL}$, and the trough level of tacrolimus was lowered. It continued to increase to $4.3 \mathrm{mg} / \mathrm{dL}$, and she was referred to nephrologists. Although multidisciplinary nephrological treatment was launched, hemodialysis had to be initiated only a year after the first nephrological referral

\section{Discussion}

The current case developed end-stage renal disease (ESRD), although her blood pressure had been consistently well-controlled by angiotensin-converting enzyme inhibitors and she had presented no signs suggestive of scleroderma renal crisis. Thus, ESRD in our case might be due to post-lung transplant CKD rather than to scleroderma renal crisis. A series of retrospective studies of a large cohort from European countries or a single high-volume institution in the USA implied comparable survival, graft prognosis of lung transplant recipients [5-7], suggesting a rising possibility that lung transplantation is appropriate for SSc patients regardless of the severe complications such as esophageal dysfunction. In Japan, until the end of 2017, 388 recipients had obtained donor lungs from deceased donors, while 208 had done so from living donors (www.asas.or.jp/jst/pdf/factbook/factbook2018 (in Japanese) [accessed October 6, 2019]). While the overall international 5-year survival rate after lung transplantation is approximately $50 \%[8,9]$, the 5 -year survival rates of recipients of living donor and deceased-donor lung transplantation in Japan are $73 \%$ and $72 \%$ (www.asas.or.jp/jst/pdf/factbook/factbook2018 (in Japanese) [accessed October 6, 2019]), respectively, as of 2017. As recipient life span is prolonged, the incidence of post-transplant CKD is increased [3]. CKD following organ transplantation is caused mainly by nephrotoxicity of calcineurin inhibitors (CNIs) but also that of antibiotics, atherosclerotic vascular disease, diabetes, and hypertension [10].
There have not yet been established standards as to which modality of RRT is the most appropriate for post-lung transplant patients with SSc. Previously, kidney transplantation in SSc patients had been reported to have poorer patient and graft survival rates than in other primary renal diseases [11]. On the other hand, recently, one report suggested no inferior prognosis under the circumstances of well-controlled pulmonary parenchymal involvement [12]. Another report suggested that patients with SSc are more likely to recover from ESRD than other nephrotoxic diseases over a year. In other words, we can estimate whether ESRD would be prospectively permanent and start to take measures to find donor candidates during that period [13]. Also, several reports suggested that patients who underwent kidney transplantation after lung transplantation revealed a significant survival profit compared with patients after lung-only transplantation [14, 15]. However, according to the Japan Organ Transplant Network, the average waiting time of adult candidates in Japan is over 14 years (https://www.jotnw.or.jp/ (in Japanese) [accessed July 29th, 2020]). She also had no close relatives eligible to become a living donor. Therefore, kidney transplantation was not appropriate.

PD could be an optimal initial modality as it might affect hemodynamics more mildly than HD [16], especially in patients complicated with pulmonary hypertension. Although there was no report intensively focusing on the efficacy and safety of PD for postlung transplant patients, one report proposed a lower 
hospitalization rate in heart and lung transplant patients on PD compared to HD [17]. It also suggested noninferior survival rates within the two modalities [17]. For patients with SSc, however, the peritoneal function might be impaired due to microvascular occlusion and fibrosis [18], and serious gastrointestinal involvements such as bowel perforation, consequent peritonitis and reduction of peritoneal clearances could be possible [19]. Additionally, our case may have an increased risk of intraperitoneal, tunnel, and exit-site infections potentially caused by multiple immunosuppressive medicines such as steroids, CNI, and mycophenolate mofetil against graft rejection after lung transplantation. Practically, manipulating the PD catheter and bags, as well as keeping chronic exit-site care aseptic is sometimes difficult for patients with SSc because of digital contracture, as is the case in our patient.

Thus, maintenance HD was considered as the appropriate option as her RRT modality. We thereafter considered what kind of vascular access to conduct HD was most suitable for the patient.

For patients with SSc, creating and maintaining vascular access is reported as clinical difficulties such as the failure of fistula attempts [20], surgical wound healing [21], and occlusive arterial disease [22], which may be due to circulating fibrotic and angiogenic molecules [23]. Antiphospholipid antibodies may be partially involved in the pathogenesis of vascular events in SSc [24]. Abnormal endothelial function impairs vasodilation through the bloodstream in patients with systemic sclerosis [25]. There still is no data reporting the outcomes of dialysis fistula formation in this population, but events due to atherosclerotic and structural vascular disease are well described in patients with SSc [26]. Immunosuppressant of CNI and mycophenolate mofetil both may not only increase the risk of infection but also delay wound healing [27, 28]. Therefore, since the surgical incision should be minimized, brachiocephalic AVF was selected to create as her vascular access.

Also, pulmonary hypertension may be exacerbated after creating AVF via a blood flow excess and heart failure $[29,30]$. In 2005, for example, Nakhould et al. illustrated that $20(48 \%)$ out of 42 hemodialysis patients had pulmonary hypertension [29]. Temporary closure of the vascular access by a sphygmomanometer in eight patients with pulmonary hypertension resulted in a transient decrease in cardiac output and systolic pulmonary arterial pressure [29]. Bolignano et al. also reported two ESRD cases with AVF who required ligation of their AVF due to the development of high-output heart failure and progressive pulmonary hypertension in the early post-operative period [30]. Thus, in performing surgery to create AVF especially for those who initially represent pulmonary hypertension, the venous diameter of AVF should be determined to avoid the cardiac complication and careful monitoring of the pressure with ultrasonography is needed for non-invasively diagnosing the pulmonary complication.

\section{Mini review}

In order to evaluate how appropriate our choice of HD as the modality of RRT utilizing brachiocephalic AVF was, we conducted a literature review describing ESRD case with either SSc or post-lung transplantation. Although a cohort data is available on clinical outcome of SSc patients requiring RRT [32], as far as we conducted a literature review providing detailed clinical course around introducing RRT for ESRD patients with SSc or lung transplantation, two case reports regarding the former only were published (Table 1) [20,31].

In 2012, Brown et al. presented a case of a 51-yearold female who suffered from polyarthritis and was prescribed with oral steroidal therapy for a provisional diagnosis of rheumatoid arthritis [20]. She afterward developed malignant hypertension and pulmonary edema, which required intubation and hemofiltration, and eventually, she was introduced PD. Although not mentioned, the scleroderma renal crisis was suggested based on the history. During the dramatic clinical course, her immunological laboratory findings revealed both of speckled and nucleolar pattern of antinuclear antibody, concurrent with Raynaud's phenomenon and digital contracture with thick skin. She was diagnosed with SSc and went on low dose oral prednisolone, and consequently, arthritis, as well as the excess of body fluid, was well controlled. Sixtyfour months after initiation of PD she had to transfer from PD to HD because of displaced PD catheter. Unfortunately, her brachiocephalic AVF got ruined by thrombosis, so she had no choice but to give up AVF and be placed dialysis catheter for HD. She died 2 years after initiation of HD, during which encapsulating peritoneal sclerosis, as well as miserable complications of chemotherapy against breast cancer, seemed to make her quality of life much worse.

In 2019, Uwatoko et al. reported a case of a 44year-old female who had developed scleroderma renal crisis several times and was introduced HD for ESRD [31]. The patient had been diagnosed with SSc based on Raynaud's phenomenon, skin stiffness, and serum positivity for anti-Scl-70 antibody 2 years before initiation of HD. She was started on oral prednisolone of $20 \mathrm{mg} /$ day but experienced the first attack of scleroderma renal crisis a year after. Although the consequent introduction of angiotensin-converting enzyme 
Table 1 Review of the literature on clinical challenges of renal replacement therapy for patients with end-stage renal disease and systemic scleroderma

\begin{tabular}{|c|c|c|c|c|c|c|c|}
\hline Reference & Age & Sex & SRC & $\begin{array}{l}\text { Lung } \\
\text { Tx }\end{array}$ & RRT & Challenges & Outcome \\
\hline [20] & 51 & Female & Yes & No & $\begin{array}{l}\text { PD for } 64 \text { months and consequent } \\
\text { transfer to HD for } 2 \text { years until } \\
\text { death }\end{array}$ & $\begin{array}{l}\text { Displaced PD catheter, EPS, abandoned brachiocephalic } \\
\text { AVF by thrombosis }\end{array}$ & Dead \\
\hline [31] & 44 & Female & Yes & No & $H D$ & $\begin{array}{l}\text { Venous rupture during creation of radiocephalic AVF, } \\
\text { delayed and poor maturation of AVF, restricted blood flow } \\
\text { rate }\end{array}$ & Alive \\
\hline $\begin{array}{l}\text { Current } \\
\text { case }\end{array}$ & 51 & Female & No & Yes & $H D$ & Cephalic vein stenosis & Alive \\
\hline
\end{tabular}

AVF arteriovenous fistula, $H D$ hemodialysis, $P D$ peritoneal dialysis, $R R T$ renal replacement therapy, $S R C$ scleroderma renal crisis, $T x$ transplantation

inhibitor made her blood pressure consistently wellcontrolled, her renal function deteriorated rapidly, which was rationally concluded as the second attack of scleroderma renal crisis because of pathological findings of malignant hypertension proved by renal biopsy. During the operation to create radiocephalic AVF, the more extensive surgical skin incision was necessary to obtain a wider view of the surgical site because of skin stiffness. Besides, her cephalic vein was accidentally ruptured despite the protective technique. The AVF was narrowly created successfully via attentive suturing. Although the preoperative diameters of arterial and venous vessels were $2.5 \mathrm{~mm}$ and $2.4 \mathrm{~mm}$, respectively, and estimated brachial arterial flow was $634 \mathrm{~mL} / \mathrm{min}$, indeed all of which were thought to be eligible for AVF, it needed approximately 4 weeks to mature well enough to puncture with ultrasound guidance. Maximum utilized blood flow of AVF was no more than $180 \mathrm{~mL} / \mathrm{min}$ and it fluctuated during HD.

Compared to those two cases, our case is unique in the following points. First of all, although not renal biopsy-proven, no sign or evidence suggestive of scleroderma renal crisis was observed. Secondly, the creation and maturation of AVF as well as initiating HD was successful and uneventful. Lastly, but most importantly, our patient had undergone lung transplantation before initiation of RRT. It could be said that rather than SSc or scleroderma renal crisis, some agents or procedures of lung transplantation might have predisposed more the patient to ESRD. Moreover, it turned out to be the case that intensive consideration of avoiding PD as well as radiocephalic AVF made it possible to safely introduce RRT when selecting the modality of RRT for our patient. We still need to intensively follow the case up to prevent stenosis and thrombosis of the brachiocephalic AVF, as reported previously. In order to establish the most suitable modality of RRT for patients with SSc or organ transplantation, more research and case reports are desirable.

\section{Conclusion}

The overall prognosis of patients with SSc has been steadily improved. As the life span of patients with SSc is prolonged, there is an increasing necessity for pursuing an optimal modality of RRT as well as developing a better reno-protective strategy against pre-dialysis CKD. Our case can exemplify these recent trends and encourage further research and development. We suggest that more case reports should be accumulated to establish the most suitable modality of RRT for patients with SSc or lung transplantation, the number of whom is now on the rise.

\section{Abbreviations \\ AVF: Arteriovenous fistula; CKD: Chronic kidney disease; CNI: Calcineurin inhibitor; ESRD: End-stage renal disease; HD: Hemodialysis; PD: Peritoneal dialysis; RRT: Renal replacement therapy; SSc: Systemic scleroderma}

\section{Acknowledgements}

We would like to thank Dr. Yoshinori Okada, Dr. Tetsu Sado, and Dr. Masafumi Noda at the Department of Thoracic Surgery, Tohoku University, Japan, for the management of lung transplant.

\section{Authors' contributions}

$\mathrm{TI}$ and $\mathrm{HA}$ acquired the data and drafted the manuscript. HN, KH, M Nakamura, JS, KY, MS, and M Nangaku revised the manuscript. All authors read and approved the final manuscript.

\section{Funding}

Not applicable.

\section{Availability of data and materials}

All data and materials were included in the manuscript.

\section{Ethics approval and consent to participate}

Written informed consent was obtained from the patient. For this type of case report, formal consent from a local ethics committee is not required.

\section{Consent for publication}

Written informed consent was obtained from the patient for the publication of this case report and any accompanying data.

\section{Competing interests}

The authors declare that they have no competing interests.

\section{Author details}

'Division of Nephrology and Endocrinology, The University of Tokyo Graduate School of Medicine, 7-3-1 Hongo, Bunkyo-ku, Tokyo 113-8655, Japan. ${ }^{2}$ Department of Radiology, The University of Tokyo Graduate School of Medicine, 7-3-1 Hongo, Bunkyo-ku, Tokyo, Japan. ${ }^{3}$ Division of Vascular 
Surgery, The University of Tokyo Graduate School of Medicine, Tokyo, Japan. ${ }^{4}$ Department of Thoracic Surgery, The University of Tokyo Graduate School of Medicine, 7-3-1 Hongo, Bunkyo-ku, Tokyo, Japan.

Received: 13 April 2020 Accepted: 22 September 2020

Published online: 06 October 2020

\section{References}

1. Traub YM, Shapiro AP, Rodnan GP, Medsger TA, McDonald RH Jr, Steen VD, et al. Hypertension and renal failure (scleroderma renal crisis) in progressive systemic sclerosis. Review of a 25-year experience with 68 cases. Medicine (Baltimore). 1983;62(6):335-52.

2. Denton CP. Renal manifestations of systemic sclerosis--clinical features and outcome assessment. Rheumatology (Oxford). 2008;47(Suppl 5):v54-6.

3. Ojo AO, Held PJ, Port FK, Wolfe RA, Leichtman AB, Young EW, et al. Chronic renal failure after transplantation of a nonrenal organ. N Engl J Med. 2003; 349(10):931-40.

4. Galie N, Humbert M, Vachiery JL, Gibbs S, Lang I, Torbicki A, et al. 2015 ESC/ ERS Guidelines for the diagnosis and treatment of pulmonary hypertension: the Joint Task Force for the Diagnosis and Treatment of Pulmonary Hypertension of the European Society of Cardiology (ESC) and the European Respiratory Society (ERS): Endorsed by: Association for European Paediatric and Congenital Cardiology (AEPC), International Society for Heart and Lung Transplantation (ISHLT). Eur Heart J. 2016;37(1):67-119.

5. Miele CH, Schwab K, Saggar R, Duffy E, Elashoff D, Tseng CH, et al. Lung transplant outcomes in systemic sclerosis with significant esophageal dysfunction. A comprehensive single-center experience. Ann Am Thorac Soc. 2016;13(6):793-802.

6. Crespo MM, Bermudez CA, Dew MA, Johnson BA, George MP, Bhama J, et al. Lung transplant in patients with scleroderma compared with pulmonary fibrosis. Short- and long-term outcomes. Ann Am Thorac Soc. 2016;13(6):784-92.

7. Pradere P, Tudorache I, Magnusson J, Savale L, Brugiere O, Douvry B, et al. Lung transplantation for scleroderma lung disease: an international, multicenter, observational cohort study. J Heart Lung Transplant. 2018;37(7): 903-11.

8. Christie JD, Edwards LB, Kucheryavaya AY, Aurora P, Dobbels F, Kirk R, et al. The Registry of the International Society for Heart and Lung Transplantation: twenty-seventh official adult lung and heart-lung transplant report--2010. J Heart Lung Transplant. 2010;29(10):1104-18.

9. Yeung JC, Keshavjee S. Overview of clinical lung transplantation. Cold Spring Harb Perspect Med. 2014;4(1):a015628.

10. Paradela de la Morena M, De La Torre BM, Prado RF, Roel MD, Salcedo JA, Costa EF, et al. Chronic kidney disease after lung transplantation: incidence, risk factors, and treatment. Transplant Proc. 2010;42(8):3217-9.

11. Bleyer AJ, Donaldson LA, McIntosh M, Adams PL. Relationship between underlying renal disease and renal transplantation outcome. Am J Kidney Dis. 2001;37(6):1152-61.

12. Bertrand D, Dehay J, Ott J, Sberro R, Brunelle C, Kamar N, et al. Kidney transplantation in patients with systemic sclerosis: a nationwide multicentre study. Transpl Int. 2017;30(3):256-65.

13. Woodworth TG, Suliman YA, Li W, Furst DE, Clements P. Scleroderma renal crisis and renal involvement in systemic sclerosis. Nat Rev Nephrol. 2016; 12(11):678-91.

14. Lonze BE, Warren DS, Stewart ZA, Dagher NN, Singer AL, Shah AS, et al. Kidney transplantation in previous heart or lung recipients. Am J Transplant. 2009;9(3):578-85

15. Osho AA, Hirji SA, Castleberry AW, Mulvihill MS, Ganapathi AM, Speicher PJ, et al. Long-term survival following kidney transplantation in previous lung transplant recipients-an analysis of the unos registry. Clin Transplant. 2017; 31(5):e12953.

16. Pavan M, Aiyangar A, Chaudhari A, Rajputh P, Ranganath R, Babulal SA. Management of scleroderma-related end-stage renal disease with automated peritoneal dialysis. Iran J Kidney Dis. 2010;4(2):162-3.

17. Guru P, Prakash R, Sheth H, Bender F, Burr R, Piraino B. Comparison of survival of patients with heart and lung transplants on peritoneal dialysis and hemodialysis. Perit Dial Int. 2015;35(1):98-101.

18. Nolph KD, Miller L, Husted FC, Hirszel P. Peritoneal clearances in scleroderma and diabetes mellitus: effects of intraperitioneal isoproterenol. Int Urol Nephrol. 1976;8(2):161-9.
19. Level C, de Precigout V, Lasseur C, Hachem D, Berge F, Larroumet N, et al. Spontaneous rupture of the esophagus (Boerhaave syndrome) in a patient with scleroderma treated by continuous ambulatory peritoneal dialysis. Rev Med Interne. 1997:18(7):566-70.

20. Brown N, Summers A, Venning MC, Bruce IN. The challenges of dialysis in systemic sclerosis: between the devil and the deep blue sea? Case Rep Nephrol. 2012;2012:865193.

21. Buscemi S, De Luca S, Fazzotta S, Lo Monte Al. Platelet-rich gel for the adjuvant treatment of wound healing of transposed flap for arteriovenous fistula in systemic scleroderma. J Vasc Access. 2017;18(3):e33-e4.

22. Roberts $\mathrm{H}$, Curnow PA. Unilateral limited scleroderma-like changes following formation of an arteriovenous fistula. Australas J Dermatol. 2007;48(1):37-9.

23. Guiducci S, Distler O, Distler JH, Matucci-Cerinic M. Mechanisms of vascular damage in SSc--implications for vascular treatment strategies. Rheumatology (Oxford). 2008;47(Suppl 5):v18-20

24. Marie I, Jouen F, Hellot MF, Levesque H. Anticardiolipin and anti-beta2 glycoprotein I antibodies and lupus-like anticoagulant: prevalence and significance in systemic sclerosis. Br J Dermatol. 2008;158(1):141-4.

25. Bartoli F, Blagojevic J, Bacci M, Fiori G, Tempestini A, Conforti ML, et al. Flow-mediated vasodilation and carotid intima-media thickness in systemic sclerosis. Ann N Y Acad Sci. 2007;1108:283-90.

26. Au K, Singh MK, Bodukam V, Bae S, Maranian P, Ogawa R, et al. Atherosclerosis in systemic sclerosis: a systematic review and meta-analysis. Arthritis Rheum. 2011;63(7):2078-90.

27. Dean PG, Lund WJ, Larson TS, Prieto M, Nyberg SL, Ishitani MB, et al. Wound-healing complications after kidney transplantation: a prospective, randomized comparison of sirolimus and tacrolimus. Transplantation. 2004; 77(10):1555-61.

28. Kuppahally S, Al-Khaldi A, Weisshaar D, Valantine HA, Oyer P, Robbins RC, et al. Wound healing complications with de novo sirolimus versus mycophenolate mofetil-based regimen in cardiac transplant recipients. Am J Transplant. 2006;6(5 Pt 1):986-92.

29. Nakhoul F, Yigla M, Gilman R, Reisner SA, Abassi Z. The pathogenesis of pulmonary hypertension in haemodialysis patients via arterio-venous access. Nephrol Dial Transplant. 2005;20(8):1686-92.

30. Bolignano D, Rastelli S, Agarwal R, Fliser D, Massy Z, Ortiz A, et al. Pulmonary hypertension in CKD. Am J Kidney Dis. 2013:61 (4):612-22.

31. Hruskova Z, Pippias M, Stel VS, Abad-Diez JM, Benitez Sanchez M, Caskey FJ, et al. Characteristics and outcomes of patients with systemic sclerosis (scleroderma) requiring renal replacement therapy in Europe: results from the ERA-EDTA Registry. Am J Kidney Dis. 2019;73(2):184-93.

32. Uwatoko M, Obo R, Otsuka A, Abe M, Yoshimine Y, Oku M, et al. A case of scleroderma renal crisis involving difficulties with selecting a dialysis method and making an arteriovenous fistula for hemodialysis (in Japanese). J Jpn Soc Dial Ther. 2019;52(6):363-8.

\section{Publisher's Note}

Springer Nature remains neutral with regard to jurisdictional claims in published maps and institutional affiliations.

Ready to submit your research? Choose BMC and benefit from:

- fast, convenient online submission

- thorough peer review by experienced researchers in your field

- rapid publication on acceptance

- support for research data, including large and complex data types

- gold Open Access which fosters wider collaboration and increased citations

- maximum visibility for your research: over $100 \mathrm{M}$ website views per year

At $\mathrm{BMC}$, research is always in progress.

Learn more biomedcentral.com/submission 